\title{
Drought adaptive prediction in potato (Solanum tuberosum) using in vitro and in vivo approaches
}

\author{
JANE KATHRYNE JOLANDA LAISINA ${ }^{1,2, \boldsymbol{\nu}}$, AWANG MAHARIJAYA ${ }^{3}$, SOBIR $^{3}$, AGUS PURWITO ${ }^{3}$ \\ ${ }^{1}$ Graduate School, Department of Agronomy and Horticulture, Faculty of Agriculture, Institut Pertanian Bogor. Jl. Raya Dramaga, IPB University \\ Campus Dramaga, Bogor 16680, West Java, Indonesia. Tel./fax.: +62-251) 8622642, `email: janelaisina@ yahoo.co.id \\ ${ }^{2}$ Breeding and Biotechnology Program, Faculty of Agriculture, Universitas Pattimura. Jl. Ir. M. Putuhena, Poka Campus, Ambon 97233, Maluku, \\ Indonesia \\ ${ }^{3}$ Department of Agronomy and Horticulture, Faculty of Agriculture, Institut Pertanian Bogor. Jl. Meranti, IPB University Campus Dramaga, Bogor \\ 16680, West Java, Indonesia
}

Manuscript received: 15 November 2020. Revision accepted: 6 January 2021.

\begin{abstract}
Laisina JKJ, Maharijaya A, Sobir, Purwito A. 2021. Drought adaptive prediction in potato (Solanum tuberosum) using in vitro and in vivo approaches. Biodiversitas 22: 537-545. Prediction of drought adaptive potatoes requires selection indicators. This study aimed to determine in vitro selection indicators for obtaining drought adaptive potato genotypes in vitro and in vivo. The in vitro study was performed using single-node explants from seven genotypes cultured for six weeks on MS medium added with $0.2 \mathrm{M}$ sorbitol to achieve the research aims. The cultures were partially observed and followed by watering the in vitro tubing medium. For the in vivo study, drought stress was applied for 21 days when the plants reached 25 days after planting (DAP) and for 14 days when the plants reached 50 DAP, then plants were irrigated again until harvesting. The results showed that plant height and root length can be used as selection indicators because they had a relative decrease below 50\%, a close relationship and had the same variance with the in vitro number of tubers, in vitro tuber fresh weight and in vivo tuber fresh weight in drought stress at 25 DAP. These characters were determinant characters for the clustering pattern in the heat map cluster analysis. Based on these characters, SSI analysis was also performed and it was found that the PKHT4 was more adaptive than the PKHT6 in vitro, but the two genotypes were classified in the medium adaptive in vivo. In conclusion, plant height and root length were determined as the in vitro selection indicators in predicting drought adaptive genotypes in vivo at the plant age of 25 DAP.
\end{abstract}

Keywords: Drought adaptive, in vitro, in vivo, selection indicator, Solanum tuberosum

\section{INTRODUCTION}

Potato production (Solanum tuberosum L.) in Indonesia in 2018 has been declined from the production in 2017 about $86.88 \%$ of the target. One of the reasons was climate change, which caused erratic rainfall and drought. Drought occurs due to longer drought and higher evapotranspiration because of rising earth temperatures (Lobell et al. 2011; Tardieu 2012). Potato plants are very sensitive to drought stress (Coleman 2008; Obidiegwu et al. 2015). This is because potatoes have a shallower root system (Iwama 2008; Deguchi et al. 2015). Therefore, it is necessary to develop ideal potatoes that can maintain yields during a drought-stress condition. An ideal potato genotype is defined as an adaptive plant possessing the ability to use water efficiently when water resources are limited. To achieve that, breeders must formulate a detailed concept of the morphology, physiology, and attributes of the ideal genotype (Acquaah 2007). Adaptive plant genotype screening requires morphological assessment indicators that are useful in the selection process. In fact, the measurement of morphological characters as an indicator in the field is difficult and takes a long time. This has led many researchers to seek a faster method for screening morphological characters that will be used as selection indicators.
The in vitro selection method is developing rapidly nowadays because environmental influences can be controlled so that a homogeneous population can be created and also makes it easier to observe the root characteristics (Gopal and Iwama 2007). The in vitro drought selection method uses a selection agent in the form of an osmotic compound that can simulate drought conditions in the field. The development of an in vitro drought-tolerant potato screening method through determination of the appropriate level of sorbitol and PEG has been carried out by (Gopal and Iwama 2007), using a PEG selection agent (Anithakumari et al. 2011; Barra et al. 2013; Bai et al. 2016) and using the sorbitol selection agent to observe physiological responses in the form of proline and osmotic adjustment (Albiski et al. 2012; Bündig et al. 2016). The in vivo selection method is a method that has been widely used to examine the morphological, physiological and yield responses of tubers (Levy 1983; Levy 1992; Coleman 2008; Li et al. 2017). In vivo selection can provide a closer description of the condition in the field than in vitro selection, but in vitro selection can be used as an initial screening for large populations. In vitro and in vivo selection can use morphological characters as selection indicators. According to (Jambormias et al. 2013), a character that has no economic value can be selected as a selection indicator if it has a relationship with the economic 
value characters. Determination of selection indicators can be performed using relative decrease analysis (Bündig et al. 2016), while the relationship between in vitro selection indicators and in vivo tuber yields can be determined using multivariate analysis. According to Anshori et al. (2020) and Fadhli et al. (2020) multivariate analysis can simplify, reduce, and predict the relationship among many variables and objects.

The effect of drought varies depending on the stage of plant growth and development (Acquaah 2007; Obidiegwu et al. 2015). Therefore, it is necessary to ensure that the indicated drought adaptive genotype in vitro is an indicated drought adaptive genotype in vivo in the vegetative phase and the rooting phase, and to ensure the characters used as selection indicators can be used in the in vivo selection. It is important to conduct an examination in vivo because the drought response in vitro is the response of plantlets which are heterotrophic plants. Meanwhile, the response of plants in vivo is the response of autotrophic plants, so that there may be a difference in response. If a genotype has the same adaptive response both in vitro and in vivo, then the selection accuracy of the adaptive genotype will be higher. Previous in vitro drought selection studies only reached drought screening on germination media and were not followed up by investigation at the in vitro tubing yields, so that the certainty of in vitro characters as selection indicators that were positively correlated with in vitro rooting was not obtained. To answer the above problems, the aims of this study were to obtain characters that can be used as selection indicators in the in vitro germination induction media and to describe the relationship between the indicated characters as in vitro selection indicators and both in vitro and in vivo tuber yields. Therefore, drought adaptive genotype prediction in vivo, besides using tuber yields, can also be performed using vegetative characters in vitro. The results of this study are expected to provide basic information in a faster and easier process of forming drought adaptive potato genotypes.

\section{MATERIALS AND METHODS}

\section{Study area}

The experiment was conducted at the Laboratory of Center for Tropical Horticulture Studies (CTHS/PKHT), IPB University, Bogor, Indonesia starting from February 2018 to August 2019. Experiments for in vivo screening of drought-tolerant potato were performed at the PT Champ screen house in Tambakbaya Village, Cisurupan Subdistrict, Garut District, West Java, Indonesia with altitude between 1,000-1,300 m asl starting from November 2019 to February 2020.

\section{Procedures Genotype}

This study used seven potato genotypes consisting of five potatoes in vitro genotype collections, namely PKHT3, PKHT4, PKHT6, PKHT9, and PKHT10; and two commercial genotypes (Granola and Atlantic) as a comparison. For the in vivo, four PKHT genotypes
(PKHT4, PKHT6, PKHT7, PKHT9) and two commercial genotypes (Granola and Atlantic) as a comparison were used. The six genotypes in the PKHT laboratory collections were the breeding results of Center for Tropical Horticulture Studies, and Agronomy and Horticulture Department, IPB University, Bogor, Indonesia, and their performance has been well studied (Table 1).

\section{In vitro drought adaptive screening}

The experiment was started with plant propagation. Plant propagation using the basic media of Murashige Skoog (MS), sucrose 30 g. $\mathrm{L}^{-1}$ and a solid agar compactor 7 g. $\mathrm{L}^{-1}$. Plants were cultured in propagation media for three weeks. Afterward, their shoot cuttings were transferred to the treatment medium. The results of research by Gopal and Iwama (2007) and Bundig et al. (2016) showed that 0.2 $M$ sorbitol can be used as a drought induction agent in potato micro cuttings induction media. Sorbitol with concentration of $0.2 \mathrm{M}$ was used as a dryness induction agent in potato micro-cuttings induction medium. The composition of the in vitro screening media followed the previous study conducted by Gopal and Iwama (2007) in the form of MS + sucrose 30 g. $\mathrm{L}^{-1}+$ agar 7 g. $\mathrm{L}^{-1}+$ sorbitol $0.2 \mathrm{M}$ with the water potential of-1.35 $\mathrm{MPa}$. Before being transferred to a culture bottle (size $150 \mathrm{~mm} \times 25 \mathrm{~mm}$ ), the $\mathrm{pH}$ of media was adjusted to $5.7 \pm 1.0$. Only shoots were transferred to the treatment medium and were cultured at temperature of $19.7-20^{\circ} \mathrm{C}$ for six weeks with 24-hour irradiation using white fluorescent lamps that generated $100 \mu \mathrm{mol} \mathrm{m}-{ }^{2} \mathrm{~s}^{1}{ }^{1}$ per day.

The 6-weeks after planting (WAP) aged plantlets were taken out of the bottle. For each plantlet per genotype, the foliage was cut from the roots and the plantlet height was measured as the main stem length from the base to the tip. The sample was weighed as the foliage fresh weight, and after drying it was weighed as the foliage dry weight. The roots were washed to remove the sticky agar medium. The samples were measured for the root length and weighed as the root fresh weight, and after drying it was weighed as the root dry weight. To obtain dry weight, the foliages and roots were dried using an oven at $70{ }^{\circ} \mathrm{C}$ for 48 hours.

Table 1. The performance of the seven genotypes of potato G1 (Neni et al. 2018)

\begin{tabular}{lccc}
\hline Genotype & $\begin{array}{c}\text { Plant } \\
\text { height }(\mathbf{c m})\end{array}$ & $\begin{array}{c}\text { Harvesting age } \\
\text { (DAP) }\end{array}$ & $\begin{array}{c}\text { Yield per } \\
\text { hectare (ton) }\end{array}$ \\
\hline PKHT3 & Short & 110 & 1.47 \\
PKHT4 & Short & 110 & 2.74 \\
PKHT6 & Short & 110 & 18.32 \\
PKHT9 & Short & 110 & 1.92 \\
PKHT10 & Short & 110 & 5.14 \\
Granola & Short & 100 & 0.04 \\
Atlantic & Short & 110 & 0.062 \\
\hline
\end{tabular}

Note: Based on UPOV (International union for the protection of new varieties of plant), very short $<44 \mathrm{~cm}$; short $44-49.9 \mathrm{~cm}$; medium $50-54.9 \mathrm{~cm}$; high $55-59.5 \mathrm{~cm}$; very high $>59.9 \mathrm{~cm}$. 
In vivo drought adaptive screening

Experiments were conducted in a screen house at average temperature and humidity of the last span of 10 days (dasarian III) in November and December of $31.9^{\circ} \mathrm{C}$ and $46.9 \%$, January of $25.6{ }^{\circ} \mathrm{C}$ and $72.2 \%$, February of $23.3{ }^{\circ} \mathrm{C}$ and $90.3 \%$. In vivo drought-tolerant potato screening was performed at the nursery stage to produce $G_{0}$ seeds. Plantlet from the tissue culture was removed from the bottle and then was acclimatized until the plants were 21 DAP. Two small pieces of shoots were then cut and acclimatized. This process was repeated three times. The plants were transferred and planted in one-kilogram polybags using sterilized rice husk media. A hole with a diameter of one $\mathrm{cm}$ was made on the left and right sides of the polybags. Irrigation was performed by administering nutrients in the morning and pure water at noon, but when the humidity was high, irrigation at noon was eliminated. Nutrition was made based on Standard Operating Procedures (SOP) applied at the PT Champ Garut nursery (Table 2).

The experiment used a completely randomized design with two treatments consisting of drought starting at plants aged 25 DAP and 50 DAP. Each treatment was repeated four times for each genotype. When entering the research treatment stage, the plants were divided into three groups. According to Coleman (2008), in vivo drought treatment was obtained through non-irrigated plants for 21 days, so in this study, the first group was not irrigated for 21 days when the plants were 25 days old, the second group was not irrigated for 14 days when the plants were 50 days old, and the third group was irrigated daily according to the SOP used as a control. After 21 days of drought treatment, the irrigation was reperformed until harvest, in which the amount of watering was according to the plant age (Table 2).

The tubers were harvested, then the tuber fresh weight per plant was measured. The number of tubers per plant and the tuber dry weight were calculated after the tubers were dried in an oven at $100{ }^{\circ} \mathrm{C}$ for 48 hours.

\section{Data analysis}

Data processing was performed using SAS 9.1.3 software to analyze the variance (ANOVA). The analysis of the biplot main components, Spearman correlation and heatmap cluster were performed using Star software. Relative decrease was determined according to Bundig et al. (2016):

Table 2. Irrigation procedures in the nursery of potato G0

\begin{tabular}{lcc}
\hline $\begin{array}{c}\text { Plant age } \\
\text { (day) }\end{array}$ & $\begin{array}{c}\text { Nutrition (liter) in } \\
\text { the morning / 36 } \\
\text { polybags }\end{array}$ & $\begin{array}{c}\text { Pure water (liter) at } \\
\text { noon / 36 polybags }\end{array}$ \\
\hline $0-30$ & 3 & 2 \\
$31-60$ & 3 & 3 \\
$61-85$ & 4 & 4 \\
$86-90$ & 2 & 2 \\
$90-$ harvest & Dried & Dried \\
\hline
\end{tabular}

$\mathrm{PR}=\frac{p 0-p s}{p 0} \times 100 \%$

Where:

P0: the observed characters in the control

Ps: the observed characters in sorbitol concentrations

Determination of sensitive and adaptive potato genotypes was performed using the stress susceptibility index (SSI) test according to Fischer and Maurer (1978):

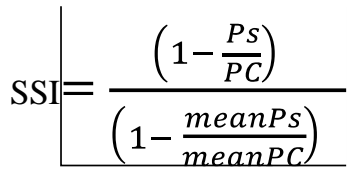

Where:

Ps: the observed characters in the sorbitol

Pc: the observed characters in the control

Mean Ps: mean of all genotypes in the sorbitol

Mean Pc: mean of all genotypes in the control

\section{RESULTS AND DISCUSSION}

\section{Morphological responses of seven potato genotypes in $0.2 \mathrm{M}$ sorbitol medium in vitro}

The results of the analysis of variance showed that the tested genotypes (Table 3 ) were very significantly different $(\mathrm{P}<001)$ in the character of plant height $(0.83)$ and root length (2.52), while sorbitol as a selection agent was very significantly different $(\mathrm{P}<001)$ in the character of plant height (5.24) and significantly different in the character of the root length (0.10). Likewise, the interaction between genotype and sorbitol (GXS) only occurred in both characters of plant height (0.21) and root length (1.17), while the characters of foliage fresh weight, foliage dry weight, root fresh weight and root dry weight had no interaction between genotype and sorbitol. Therefore, the best genotypes in the control were also the best genotypes when stressed by drought.

The relative decrease analysis results showed that the character of plant height and root length was below $50 \%$. The relative decrease of the two characters was $46.79 \%$ and $42.76 \%$, respectively. Although the relative decrease in foliage dry weight was the lowest, the ANOVA showed that there was no interaction between the tested genotypes and sorbitol for this character. If there was no interaction, there will be no difference in the response of the tested genotypes on media without sorbitol and media with sorbitol, so it will be difficult to select adaptive genotypes. Therefore, based on these results, plant height and root length were determined as in vitro selection indicators.

\section{Yield characters of potato genotypes in response to drought condition}

The ANOVA results in Table 4 showed the different responses of potato tubing among genotypes grown both in vitro and in vivo at drought conditions. In this term, we compared those yield characters of in vitro plantlets at vegetative growth phase, 25 day-olds in vivo plants, and 50 
day-olds in vivo plants, respectively. The ANOVA results showed significant differences in response between genotypes on the three in vitro characters, in vivo drought treatment at age 25 and age 50 DAP, except that the in vitro number of tubers of genotype was not significantly different. There was no difference between control and drought stress on the in vitro number of tubers and in vivo tuber dry weight in drought stress at 25 DAP. In contrast, there was a difference between control and drought stress conditions on other characters both in vitro and in vivo in drought stress at 25 and 50 DAP. The interaction between genotype and drought was significant $(\mathrm{p}<0.005)$ differences only found on the character of the in vitro number of tubers and were very significant $(p<0.001)$ on the in vivo tuber dry weight at the age of 50 DAP. At the same time, there was no interaction with other characters.

Furthermore, to examine the relationship between in vitro selection indicators and tuber yield characters, a correlation analysis was performed. The results of the correlation analysis between plant height and root length as in vitro selection indicators and in vitro potato tubing
(Table 5 and Figure 1) showed that there was a significant correlation between plant height and the in vitro number of tubers $(r=0.992)$ and in vivo tuber fresh weight at 25 DAP $(\mathrm{r}=0.816)$. A significant correlation was also found between root length and in vitro tuber fresh weight $(\mathrm{r}=$ 1.00). The in vitro number of tubers also had a good correlation with in vivo tuber fresh weight in drought stress at 25 DAP. This relationship indicated that the in vitro characters could predict a drought tolerance in vivo at plant age of 25 days $(r=0.816)$. In vivo tuber fresh weight in drought stress at 25 DAP also had a significant correlation with its dry weight. However, in vitro plant height and root length were not significantly correlated with in vivo dry weight in drought stress at 25 DAP. All in vitro characters showed insignificant relationship on the in vivo characters in drought stress at 50 DAP. A significant relationship was only found between the characters of in vivo tuber fresh weight at 50 DAP and tuber dry weight at 50 DAS. This insignificance indicated that the in vitro drought treatments cannot predict the drought tolerance properties in vivo at plant age of 50 days.

Table 3. Analysis of variance and relative decrease in shoot and root characters of seven potato genotypes at a sorbitol concentration of $0.2 \mathrm{M}$ and control in vitro

\begin{tabular}{|c|c|c|c|c|c|c|}
\hline \multirow{2}{*}{$\begin{array}{c}\text { Source of } \\
\text { variance }\end{array}$} & \multicolumn{6}{|c|}{ ANOVA of characters } \\
\hline & PH & FFW & FDW & RL & RFW & RDW \\
\hline Genotype & $0.83 * *$ & 0.00021 & 0.00006 & $2.52 * *$ & 0.0002 & 0.0000006 \\
\hline Sorbitol & $5.24 * *$ & $0.003 * *$ & 0.00007 & $0.10^{*}$ & 0.0013 & 0.0000022 \\
\hline Interaction & $0.21 *$ & 0.0024 & 0.00005 & $1.17 *$ & 0.0001 & 0.0000009 \\
\hline $\mathrm{CV}$ & 9.508 & 1.508 & 1.182 & 26.78 & 2.51 & 0.104 \\
\hline Genotype & \multicolumn{6}{|c|}{ Relative decrease of characters } \\
\hline PKHT3 & 51.75 & 63.50 & 24.03 & 31.10 & 70.28 & 88.25 \\
\hline PKHT4 & 26.25 & 13.35 & 0 & 32.81 & 80.74 & 67.54 \\
\hline PKHT6 & 29.04 & 65.62 & 65.38 & 35.26 & 55.02 & 22.22 \\
\hline РКHT9 & 46.43 & 60.56 & 10.59 & 61.63 & 83.09 & 56.67 \\
\hline PKHT10 & 49.76 & 73.38 & 48.52 & 57.59 & 50.49 & 68.78 \\
\hline GRANOLA & 56.40 & 61.44 & 41.86 & 38.84 & 79.29 & 49.61 \\
\hline ATLANTIC & 67.92 & 77.14 & 43.69 & 42.11 & 61.70 & 53.87 \\
\hline Average & 46.79 & 59.28 & 33.41 & 42.76 & 68.66 & 58.13 \\
\hline
\end{tabular}

Note: PH: Plantlet Height (cm); FFW: Foliage Fresh Wight (g/planlet); FDW: Foliage Dry Weight (g/planlet); RH: Root Height (cm); RFW: Root Fresh Weight (mg/planlet); RDW: Root Dry Weight (mg/planlet).* significant at $\mathrm{P}<0.005$; ** very significant at $\mathrm{P}<001$; $\mathrm{CV}$ : Coefficient of Variance

Table 4. Responses of tubing of seven potato genotypes in vitro at a sorbitol concentration of $0.2 \mathrm{M}$ and drought stress for 21 days in vivo in potato plants at 25 and $50 \mathrm{DAP}$

\begin{tabular}{|c|c|c|c|c|c|c|c|c|c|}
\hline \multirow{2}{*}{ Genotype } & \multicolumn{3}{|c|}{ In vitro } & \multicolumn{3}{|c|}{$\begin{array}{c}\text { In vivo } \\
\text { Dry at } 25 \text { DAP }\end{array}$} & \multicolumn{3}{|c|}{$\begin{array}{c}\text { In vivo } \\
\text { Dry at } 50 \text { DAP }\end{array}$} \\
\hline & NTvt & TFWvt & TDWvt & NTv1 & TFWv1 & TDWv1 & NTv2 & TFWv2 & TDWv2 \\
\hline Genotype & $0.18^{\mathrm{tn}}$ & $0.11^{* *}$ & $0.02 * *$ & $2.01 * *$ & $7.73 * *$ & $1.44 * *$ & $1.56^{* *}$ & $7.34 * *$ & $1.23 * *$ \\
\hline Drought & $0.14^{\mathrm{tn}}$ & $0.08 *$ & $0.04 *$ & $1.04 *$ & $13.18 * *$ & $1.17^{\mathrm{tn}}$ & $1.48 * *$ & $35.80 * *$ & $6.73 * *$ \\
\hline Interaction & $0.21 *$ & $0.006^{\mathrm{tn}}$ & $0.006^{\text {tn }}$ & $0.460^{\operatorname{tn}}$ & $0.29^{\mathrm{tn}}$ & $0.17^{\mathrm{tn}}$ & $0.18^{\mathrm{tn}}$ & $0.55^{\mathrm{tn}}$ & $0.09 * *$ \\
\hline CV & 23.95 & 29.00 & 39.8 & 19.14 & 23.74 & 28.41 & 18.74 & 24.02 & 24.97 \\
\hline
\end{tabular}

Note: NT: Number of Tubers, TFW: Tuber Fresh Weight, TDW: Tuber Dry Weight, vt: in vitro; v1: drought treatment (without irrigation for 21 days) when the in vivo plants aged 25 days; v1: drought treatment (without irrigation for 21 days) when the in vivo plants aged 50 days.* significant at $\mathrm{P}<0.005$; ** significant at $\mathrm{P}<001 ; \mathrm{CV}$ : coefficient of variance

Table 5. The relationships based on Pearson correlation between selection indicators and tuber characters in vitro and in vivo 


\begin{tabular}{|c|c|c|c|c|c|c|c|c|c|}
\hline Character & $\mathbf{P H}$ & RL & NTVt & TFWVt & NTVv1 & TFWVv1 & TDWVv1 & NTVv2 & TFWVv2 \\
\hline$\overline{R L}$ & 0.236 & & & & & & & & \\
\hline NTVt & 0.992 & 0.150 & & & & & & & \\
\hline TFWVt & 0.236 & 1.000 & 0.150 & & & & & & \\
\hline NTVv1 & 0.303 & -0.652 & 0.303 & -0.652 & & & & & \\
\hline TFWVv1 & 0.816 & 0.455 & 0.816 & 0.455 & -0.192 & & & & \\
\hline TDWVv1 & 0.491 & 0.186 & 0.491 & 0.186 & -0.245 & 0.856 & & & \\
\hline NTVv2 & -0.257 & 0.242 & -0.246 & 0.242 & -0.035 & -0.375 & -0.562 & & \\
\hline TFWVv2 & 0.055 & 0.291 & -0.004 & 0.291 & -0.244 & 0.336 & 0.560 & -0.160 & \\
\hline TDWVv2 & 0.163 & 0.085 & 0.169 & 0.085 & -0.205 & 0.448 & 0.563 & 0.106 & 0.808 \\
\hline
\end{tabular}

Note: PH: Plant Height, RL: Root Length, NT: Number of Tubers, TFW: Tuber Fresh Weight, TDW: Tuber Dry Weight

To sharpen the relationship analysis between characters, a biplot analysis was performed (Figure 2). The biplot analysis can examine the relationship between characters without overlapping variance and determine which characters dominate the differences due to drought stress. The biplot analysis results supported the results of the correlation analysis. Most of the characters relatively had the same variance direction, except for the in vivo number of tubers at $50 \mathrm{DAP}$ and the in vivo number of tubers at 25 DAP. The same variance direction characters were obtained in in vivo tuber fresh weight at $25 \mathrm{DAP}$, in vivo tuber dry weight at 25 DAP, in vitro number of tubers, and plant height, which had the largest variance. Based on the results, the determination of adaptation properties was strongly affected by root length, plant height, in vitro number of tubers, in vitro tuber fresh weight, in vivo number of tubers at $25 \mathrm{DAP}$, in vivo tuber fresh weight at $25 \mathrm{DAP}$, in vivo tuber dry weight at $25 \mathrm{DAP}$, in vivo number of tubers at 50 DAP. However, characters with a close relationship with plant height and root length were the in vitro number of tubers, in vitro tuber fresh weight and in vivo tuber fresh weight at 25 DAP.

\section{The tolerance level to drought based on the characters of morphology, in vitro and in vivo potato tubers}

The results of the correlation and biplot analysis showed five characters that had a close relationship. To examine the clustering pattern of the five characters, a heat map cluster analysis was performed. Based on the heat map cluster analysis (Figure 3), the character of in vivo tuber fresh weight at 25 DAP was the determinant of the main clustering pattern and then sharpened by the characters of root length, in vitro tuber fresh weight, plant height, and in vitro number of tubers. These findings strengthened the analysis that the characteristics of plant height and root length, which were used as in vitro selection indicators were closely related to the in vitro tuber fresh weight and the in vivo tuber fresh weight at 25 DAP. In addition, based on the results of the heat map cluster, PKHT4 and PKHT6 were the most adaptive genotypes among the seven tested genotypes. This is in line with the relative decrease analysis results in the characters of plant height and root length (Table 3), in which the genotypes that had the lowest relative decrease were PKHT4 and PKHT6. From the average of root length characters of the PKHT4 and PKHT6, these two genotypes had the highest root length. Meanwhile, the plant height characters of PKHT4 and
PKHT6 genotypes were not the genotypes with the highest plant height. This is because each genotype has a different plant height under normal conditions.

\section{Cluster heatmap}

The tolerance level of the tested genotypes based on the morphological characters used as in vitro selection indicators at drought stress is presented in Table 6. The lowest sensitivity index on the plant height character was PKHT4, followed by PKHT6 in the tolerant category. For the root length character, the lowest sensitivity index was PKHT3, followed by PKHT4 and PKHT6, in which PKHT3 and PKHT4 were included in the tolerant category, while PKHT6 was included as medium tolerant. Although PKHT3 had the lowest sensitivity index on the root length, PKHT3 had a high sensitivity index on the character of plant height and included in the sensitive category. Likewise, for PKHT9 and PKHT10, these genotypes were tolerant on the plant height characters, but these two genotypes were categorized as sensitive plants on the root length characters. From the average root length character, PKHT4 and PKHT6 genotypes had the highest root length, while these two genotypes were not the genotypes with the highest plant height. This is because each genotype has a different plant height under normal conditions.

To determine the adaptation level between genotypes, the drought stress susceptibility index (SSI) was calculated based on the selection indicator characters and tuber characters in vitro and in vivo which were closely related (Table 6). The results of SSI calculations based on the in vitro characters showed that PKHT4 was the adaptive genotype, and PKHT4 was changed to the medium adaptive category on the in vivo tuber fresh weight character in drought stress at 25 DAP. PKHT6 was also adaptive on the characters of plant height and in vitro number of tubers, while it was included in the medium adaptive category on the characters of root length and in vitro tuber fresh weight and in vivo tuber fresh weight at 25 DAP. Other genotypes such as PKHT3 and PKHT10 were determined in the adaptive category or medium adaptive, but these genotypes were not consistent in all characters because there were sensitive categories for other characters. PKHT9, Granola and Atlantik genotypes were categorized as sensitive because these genotypes were sensitive on the in vivo tuber fresh weight at $25 \mathrm{DAP}$, although some of the in vitro characters were categorized as medium adaptive.

Table 6. Adaptation level based on selection indicators and tuber characters in vitro and in vivo which are closely related 


\begin{tabular}{|c|c|c|c|c|c|c|}
\hline \multirow{2}{*}{ Genotype } & \multicolumn{2}{|c|}{ In vitro selection indicators } & \multicolumn{2}{|c|}{ In vitro tubers } & \multirow{2}{*}{ Genotype } & \multirow{2}{*}{$\begin{array}{c}\text { In vivo tubers at } 25 \text { DAP } \\
\text { TFW }\end{array}$} \\
\hline & PH & RH & NT & TFW & & \\
\hline PKHT3 & $1.037=\mathrm{S}$ & $0.697=\mathrm{A}$ & $1.04=\mathrm{S}$ & $0.70=\mathrm{A}$ & PKHT4 & $0.82=\mathrm{MA}$ \\
\hline PKHT4 & $0.526=\mathrm{A}$ & $0.736=\mathrm{A}$ & $0.53=\mathrm{A}$ & $0.74=\mathrm{A}$ & PKHT6 & $0.83=\mathrm{MA}$ \\
\hline PKHT6 & $0.528=\mathrm{A}$ & $0.791=\mathrm{MA}$ & $0.53=\mathrm{A}$ & $0.79=\mathrm{MA}$ & PKHT7 & $0.81=\mathrm{MA}$ \\
\hline PKHT9 & $0.930=\mathrm{MA}$ & $1.382=\mathrm{S}$ & $0.93=\mathrm{MA}$ & $1.38=\mathrm{S}$ & PKHT9 & $1.11=\mathrm{S}$ \\
\hline PKHT10 & $0.997=\mathrm{MA}$ & $1.491=\mathrm{S}$ & $0.90=\mathrm{MA}$ & $1.49=S$ & Granola & $1.27=S$ \\
\hline Granola & $1.130=\mathrm{S}$ & $0.871=\mathrm{MA}$ & $1.13=\mathrm{S}$ & $0.87=\mathrm{MA}$ & Atlantic & $1.38=\mathrm{S}$ \\
\hline Atlantik & $1.361=\mathrm{S}$ & $0.944=\mathrm{MA}$ & $1.36=S$ & $0.94=\mathrm{MA}$ & & \\
\hline
\end{tabular}

Note: PH=Plant Height; RH=Root Height; NT=Number of Tuber; TFW=Tuber Fresh Weight $(\mathrm{g} /$ plant $)$; very adaptive $($ VA $)=($ SSI $<0.5)$, adaptive $(\mathrm{A})=(\mathrm{SSI}=0.51-0.75)$, medium adaptive $(\mathrm{MA})=(\mathrm{SSI}=0.76-1)$, Sensitive $(\mathrm{S})=(\mathrm{SSI}>1)$
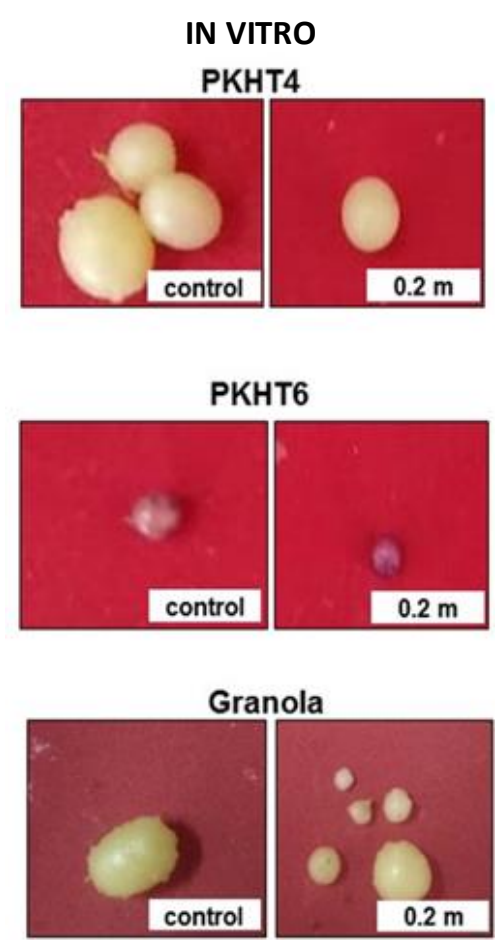

Granola

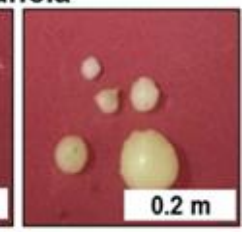

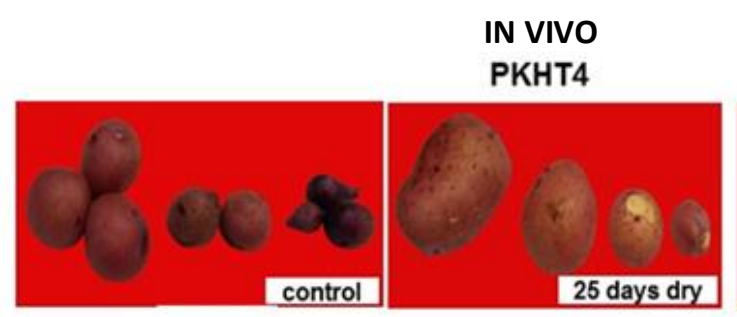

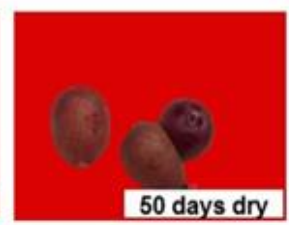

PKHT6
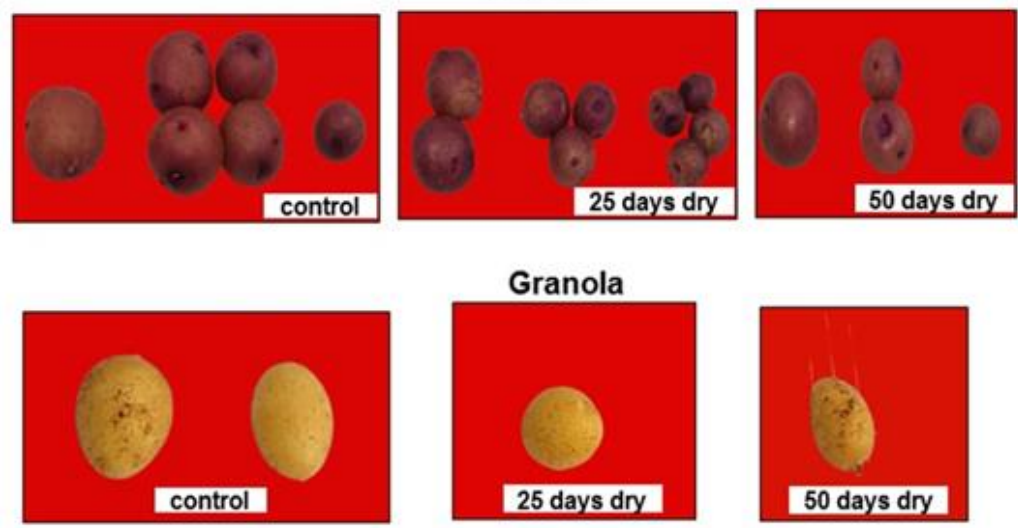

Figure 1. Potato tubing in drought media in vitro (left) and tubing in drought in vivo (right)

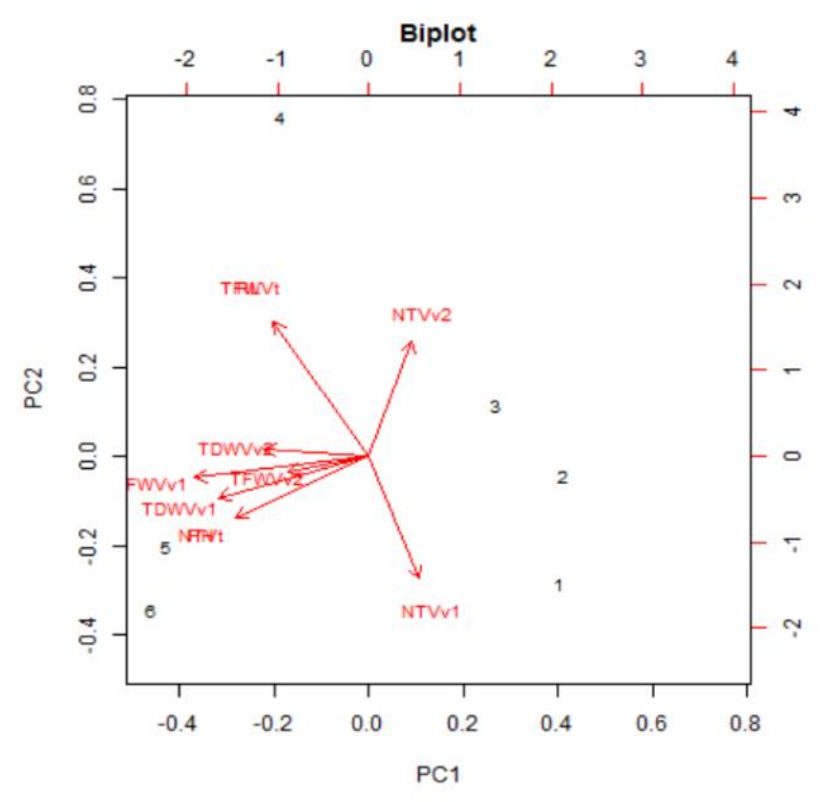

Figure 2. Biplot analysis based on selection indicators and tuber characters in vitro and in vivo. PH: Plant Height; RL: Root Length; NT: Number of Tubers; TFW: Tuber Fresh Weight (g/plant); TDW: Tuber Dry Weight (g/plant); vt: in vitro; v1: drought treatment (without irrigation for 21 days) when the in vivo plants aged 25 days; v1: drought treatment (without irrigation for 21 days) when the in vivo plants aged 50 days

\section{Discussion}

Direct selection of drought adaptive genotypes in the field has many obstacles, i.e., required water vary from year to year causing a difference in selection stress from one cycle to another and will cause loss of genetic material (Aquaa 2007), it also requires a longer time and more difficult treatment, especially for root characters (Gopal and Iwama 2007); (Levy et al. 2013; Bündig et al. 2016). Therefore, in vitro drought adaptive selection is one of promising ways to prevent loss of genetic material, accelerate and simplify the selection process. Potato drought conditions in vitro induced by sorbitol to in vitro 
media have been applied by (Gopal and Iwama 2007). They reported that $0.2 \mathrm{M}$ sorbitol could be used as a selection agent. This was later strengthened by (Albiski et al. 2012) and (Bündig et al. 2016)

Plant morphological character tolerance to drought conditions is one of the main criteria for the experimental approach (White et al. 2012). In this study, the responses of foliage and root morphological characters of in vitro plants under drought condition were shown in the analysis of variance which indicated an interaction between genotype and sorbitol only on the characters of plant height and root length (Table 3), this finding is in agreement with Gopal and Iwama (2007). The interaction means that there was a genotype with the highest root height and length in the control condition. However, in drought conditions, plant height and root length of the genotype were not the highest. The genetic diversity of varieties causes differences in plant height in cultivars (Ali et al. 2018) and it will be confusing in analyzing the adaptability if plant genotypes experienced unhomogenously plant height growth. Therefore, in assessing the adaptability to drought, the relative reduction analysis should be performed According to Bündig et al. (2016), a small relative decrease in growth indicates that these plants are more adaptive to drought than genotypes that have a greater relative decrease in growth. Relative decrease in plant height and root length characters was small below 50\% compared to other morphological characters, except for the foliage dry weight character, there was no interaction based on analysis of variance. Therefore, only the characters of plant height and root length were used for further analysis to examine the relationship with tuber characters and also in the selection of genotypes with good adaptation.

In developing potatoes that can adapt well to drought, the main goal is to achieve good tuber yields during drought conditions. Although when it compared to tuber yields without drought stress, the yields will still be lower because drought during the growth and development stage can lead to decreased quality and quantity of yields (Acquaah 2007). The results of ANOVA (Table 4) showed that all characters experienced a change in quantity under stress condition because there was a difference in the response of the tubing in genotypes due to drought, except for the character of the in vitro number of tubers and the in vivo tuber dry weight at 25 DAP. The absence of genotype and drought interaction in vivo in most tuber characters was due to the tuber yields of the genotype of the IPB PKHT collection in the control and stressed environments with higher tuber yields than the comparison genotypes. This shows the difficulties if the tuber character is used as selection indicators.

The relationship between plant height and root length as selection indicators and in vitro and in vivo tubing characters was shown in the results of the correlation analysis (Table 5) and sharpened by the biplot analysis (Figure 1). These two analyses complement each other indicating from the correlation value $(\mathrm{r}=1)$ between the characters of root length and in vitro tuber fresh weight.
The biplot analysis also described that the two characters had the same direction and magnitude so that they were overlapped. Likewise, the character of plant height had a close relationship with the in vitro number of tubers $(\mathrm{r}=$ 0.992) which also showed the same direction and almost the same magnitude so that they were overlapped with each other. Meanwhile, between plant height and in vivo tuber fresh weight in drought stress at 25 DAP $(r=0.816)$, the biplot analysis showed the two characters had a variance in the same direction and the angle between the two characters was smaller than $90^{\circ}$. According to Neni et al. (2018) and Hetharie et al. (2018), vectors between characters with an angle of $90^{\circ}$ have a distant relationship, and the farther from the point of origin, the characters will be more diverse. This means that angles smaller than $90^{\circ}$ have a close relationship and the longer vector will result in more diverse characters. In vivo tuber, fresh weight in dry stress at 25 DAP was the character with the longest vector so that this character had high diversity. In the heat map cluster, this character became the determining pattern for the main cluster and sharpened by the characters of root length, in vitro tuber fresh weight, plant height, and in vitro number of tubers. These results strengthen that root length and plant height can be used as selection indicators.

Based on the determinant characters of the main clustering pattern, the PKHT4 and PKHT6 genotypes were the most adaptive genotypes among the seven tested genotypes (Figure 2). Likewise, the analysis of the relative decrease in the characters of plant height and root length resulted in good adaptive genotypes and the lowest growth relative decrease were PKHT4 and PKHT6. From the average root length characters, the PKHT4 and PKHT6 genotypes had the highest root length. Meanwhile, the plant height characters of PKHT4 and PKHT6 genotypes were not the genotypes with the highest plant height. This is because each genotype has a different plant height under normal conditions. Although there were genotypes such as PKHT10 and PKHT9 that had a relative decrease in the plant height character below $50 \%$, the relative decrease in the root length character was more than $50 \%$. Meanwhile, PKHT3, Granola and Atlantic had a relative decrease in the root length character below $50 \%$, but the relative decrease in the plant height character for these three genotypes was above $50 \%$. If the genotype had a relative decrease of below $50 \%$ only in one of the characters used as selection indicators, then the genotype is not selected as a candidate for drought adaptive potato genotype. The selection of root length character as a selection indicator is in line with (Acquaah 2007; Gopal and Iwama 2007; Iwama 2008; Levy et al. 2013; Bündig et al. 2016) which stated that the root character is one of the important characters in the development of drought-resistant genotypes. Likewise, based on the results of SSI analysis, PKHT4 and PKHT6 were categorized as adaptive and medium adaptive genotypes. PKHT4 was more adaptive than PKHT6 in the in vitro medium, but PKHT4 and PKHT6 were classified in the same adaptation category of the medium adaptive in vivo to drought stress at $25 \mathrm{DAP}$. 


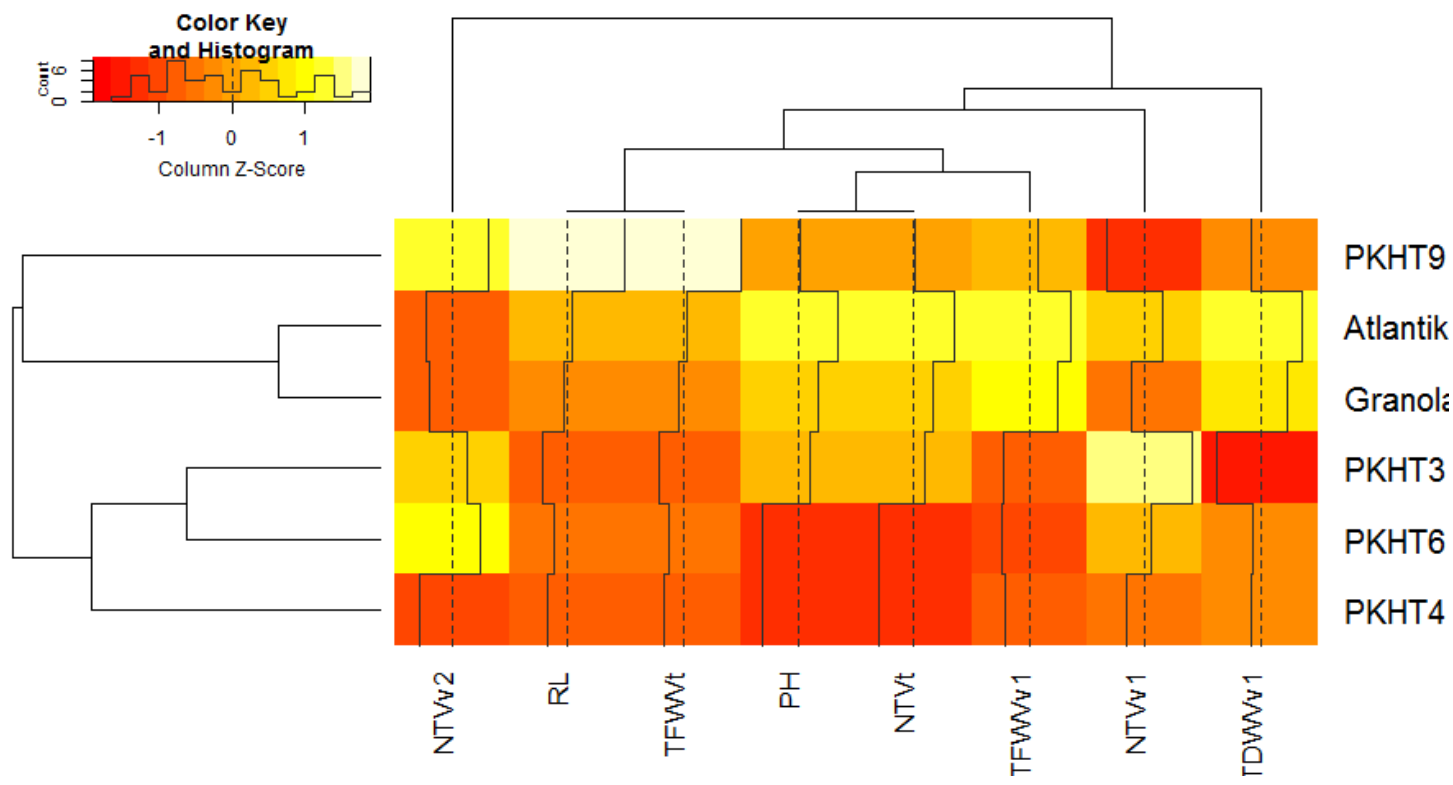

Figure 3. Classification of in vitro selection indicators and in vivo tuber characters as responses to drought stress (abscissa), and classification of drought-tolerant/adaptive and sensitive genotypes (vertical) based on the heatmap clusters

This study concluded that the determination of in vitro selection indicators based on the analysis of relative decrease, the relationship between selection indicators and tuber yield characters, and the use of SSI analysis is very useful in determining the drought adaptive genotypes. In this study, the characters of in vitro root length and plant height were determined as selection indicators because these characters could predict in vivo drought adaptation of potato at 25 DAP. However, these characters cannot predict in vivo drought adaptation of potato at 50 DAP. PKHT4 and PKHT6 were determined as drought adaptive genotypes. Characters that were used as selection indicators in this study, especially the character of plant height, should be further tested with a larger population and higher genetic diversity.

\section{REFERENCES}

Acquaah G. 2007. Principles of plant genetics and breeding. Blackwell Publishing Ltd., USA.

Albiski F, Najla S, Sanoubar R, Alkabani N, Murshed R. 2012. In vitro screening of potato lines for drought tolerance. Physiol Mol Biol Plants 18 (4): 315-321. DOI: 10.1007/s12298-012-0127-5.

Ali S, Khan N, Nouroz F, Erum S, Nasim W, Shahid MA. 2018. In vitro effects of GA3 on morphogenesis of CIP potato explants and acclimatization of plantlets in field. Vitr Cell Dev Biol Plant 54: 104111. DOI: $10.1007 / \mathrm{s} 11627-017-9874-\mathrm{x}$.

Anithakumari AM, Dolstra O, Vosman B, Visser RGF, van der Linden CG. 2011. In vitro screening and QTL analysis for drought tolerance in diploid potato. Euphytica 181 (3): 357-369. DOI: 10.1007/s10681011-0446-6.

Anshori MF, Purwoko BS, Dewi IS, Suwarno WB, Ardie SW. 2020. Cluster heatmap for detection of good tolerance trait on doubledhaploid rice lines under hydroponic salinity screening. IOP Conf Ser Earth Environ Sci 484: 1-7.DOI: 10.1088/1755-1315/484/1/012001.

Bai JP, Gao HJ, Yang HY, Lou Y, Zhang Jun Lian, Wang D, Zhang Jin Lin. 2016. Comparison of ultrastructural and physiological changes of potato (Solanum tuberosum L.) plantlets subjected to salt and modeling drought stresses. Acta Physiol Plant 38 (182): 1-9 DOI: 10.1007/s11738-016-2202-y.

Barra M, Correa J, Salazar E, Sagredo B. 2013. Response of potato (Solanum tuberosum L.) germplasm to water stress under in vitro conditions. Am J Potato Res 90 (6): 591-606. DOI: 10.1007/s12230013-9333-0.

Bündig C, Vu TH, Meise P, Seddig S, Schum A, Winkelmann T. 2016. Variability in osmotic stress tolerance of starch potato genotypes (Solanum tuberosum L.) as revealed by an in vitro screening: Role of proline, osmotic adjustment and drought response in pot trials. J Agron Crop Sci 203 (3): 206-218. DOI: 10.1111/jac.12186.

Coleman WK. 2008. Evaluation of wild Solanum species for drought resistance Solanum gandarillasii Cardenas. Environ Exp Bot 62: 221230. DOI: 10.1016/j.envexpbot.2007.08.007.

Deguchi T, Iwama K, Matsumoto M, Tanigawa J. 2015. Effect of varietal difference in root system on hydraulic conductance in potatoes under different soil water conditions and planting dates. Potato Res 58 (2): 103-119. DOI: 10.1007/s11540-015-9289-1.

Fadhli N, Farid M, Rafiuddin, Efendi R, Azrai M, Anshori MF. 2020. Multivariate analysis to determine secondary characters in selecting adaptive hybrid corn lines under drought stress. Biodiversitas 21 (8): 3617-3624. DOI: 10.13057/biodiv/d210826.

Gopal J, Iwama K. 2007. In vitro screening of potato against water-stress mediated through sorbitol and polyethylene glycol. Plant Cell Rep 26: 693-700. DOI: 10.1007/s00299-006-0275-6.

Hetharie H, Raharjo SHT, Edizon J. 2018. Morfologi components and biplot analyses of morphological characters. J Agron Indonesia 46 (3): 276-282. DOI: 10.24831/jai.v46i3.18215. [Indonesian]

Iwama K. 2008. Physiology of the potato: New insights into root system and repercussions for crop management. Potato Res 51: 333-353. DOI: 10.1007/s11540-008-9120-3.

Jambormias E, Sutjahjo SH, Mattjik AA, Wahyu Y, Wirnas D. 2013. Modification of augmented design and estimation of genetic parameters in early generation of self-pollinated crops. Jurnal Budidaya Pertanian 9 (2): 52-59. [Indonesian]

Levy D. 1983. Varietal differences in the response of potatoes to repeated short periods of water stress in hot climates. 1. Turgor maintenance and stomatal behaviour. Potato Res 26 (4): 303-313. DOI: 10.1007/BF02356152.

Levy D. 1992. Osmotic potential of potatoes subjected to a single cycle of water deficit. Potato Res 35 (1): 17-24. DOI: 10.1007/BF02357718.

Levy D, Coleman WK, Veilleux RE. 2013. Adaptation of potato to water shortage: Irrigation management and enhancement of tolerance to drought and salinity. Am J Potato Res 90: 186-206. DOI: 10.1007/s12230-012-9291-y. 
Li J, Cang Z, Jiao F, Bai X, Zhang D, Zhai R. 2017. Influence of drought stress on photosynthetic characteristics and protective enzymes of potato at seedling stage. J Saudi Soc Agric Sci 16: 82-88. DOI: 10.1016/j.jssas.2015.03.001.

Lobell DB, Schlenker W, Costa-Roberts J. 2011. Climate trends and global crop production since 1980. Science 333: 616-620. DOI: 10.1126/science.1204531.

Neni N, Maharijaya A, Syukur M. 2018. Potato G2 yield performance of IPB genotypes from cutting and tuber at Garut Jawa Barat. Bul Agrohorti 6 (3): 397-404. [Indonesian]
Obidiegwu JE, Bryan GJ, Jones HG, Prashar A. 2015. Coping with drought: Stress and adaptive responses in potato and perspectives for improvement. Front Plant Sci 6: 1-23. DOI: 10.3389/fpls.2015.00542

Tardieu F. 2012. Any trait or trait-related allele can confer drought tolerance: Just design the right drought scenario. J Exp Bot 63 (1): 25 31. DOI: $10.1093 / \mathrm{jxb} / \mathrm{err} 269$.

White JW, Andrade-Sanchez P, Gore MA, Bronson KF, Coffelt TA, Conley MM, Feldmann KA, French AN, Heun JT, Hunsaker DJ. 2012. Field-based phenomics for plant genetics research. Crop Res 133: 101-112. DOI: 10.1016/j.fcr.2012.04.003. 